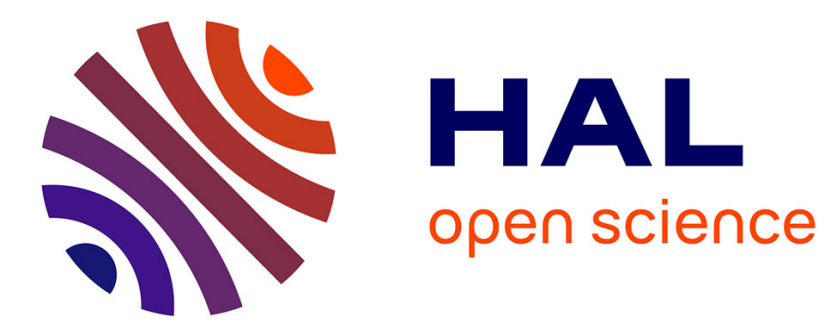

\title{
Who are bike sharing schemes members and do they travel differently? The case of Lyon's "Velo'v" scheme
}

Charles Raux, Ayman Zoubir, Mirkan Geyik

\section{To cite this version:}

Charles Raux, Ayman Zoubir, Mirkan Geyik. Who are bike sharing schemes members and do they travel differently? The case of Lyon's "Velo'v" scheme. Transportation Research Part A: Policy and Practice, 2017, 106, pp.350 - 363. 10.1016/j.tra.2017.10.010 . halshs-01639787

\section{HAL Id: halshs-01639787 https://shs.hal.science/halshs-01639787}

Submitted on 20 Nov 2017

HAL is a multi-disciplinary open access archive for the deposit and dissemination of scientific research documents, whether they are published or not. The documents may come from teaching and research institutions in France or abroad, or from public or private research centers.
L'archive ouverte pluridisciplinaire HAL, est destinée au dépôt et à la diffusion de documents scientifiques de niveau recherche, publiés ou non, émanant des établissements d'enseignement et de recherche français ou étrangers, des laboratoires publics ou privés. 


\title{
Who are bike sharing schemes members and do they travel differently? The case of Lyon's “Velo'v” scheme
}

\author{
Charles Raux ${ }^{\mathrm{a}^{*}}$, Ayman Zoubir ${ }^{\mathrm{a}}$, Mirkan Geyik ${ }^{\mathrm{a}}$ \\ ${ }^{a}$ Univ Lyon, CNRS, LAET, F-69007, LYON, France \\ * corresponding author: email: charles.raux@laet.ish-lyon.cnrs.fr, \\ address: LAET, ISH, 14 av. Berthelot, 69007 Lyon, France. \\ Phone: +33472726403, Fax: +33472726448 \\ Paper published in Transportation Research Part A \\ http://dx.doi.org/10.1016/j.tra.2017.10.010
}

How to cite:

Raux, C. Zoubir, A., Geyik, M. (2017) Who are bike sharing schemes members and do they travel differently? The case of Lyon's “Velo’v” scheme. Transportation Research Part A 106 (2017) 350-363

\begin{abstract}
This paper analyzes the socio-demographic profile and travel behavior of the "Velo'v" bike-sharing scheme annual members in Lyon (France). This scheme started in 2005 and has now around 350 stations and 4500 bikes in operation, with more than 50,000 annual members. By the means of an Internet-based survey more than 3,000 respondents were described by their detailed socio-demographic profile, their travel means and habits, a one-day activity-travel diary and additionally a seven days activity-travel diary filled by around 700 volunteers. By this way the survey covers all travel modes and day-to-day variations in travel behavior beyond the sole use of shared bike. We analyze with a discrete choice model the socio-demographic and spatial factors affecting the probability of being an annual member of the Velo'v scheme. Then we compare with descriptive statistics their daily travel behavior involving as well bike sharing as other traditional modes to the travel behavior of the general population as given with the latest Household Travel Survey available in the Lyon area (2015). The majority of Velo'v annual members are male, younger and hold higher social positions when compared with the Lyon's general population. An individual higher social position and the residential proximity to stations have both separate and positive effects on the probability of being an annual member of the service. Velo'v members are not captive from public transport, a majority of them have access to a car and they are fully multimodal in their day-to-day travel behavior. Velo'v bikes are used by them for any activity, not necessarily every day, like any other travel mode. The multimodal behavior of Velo'v members shows that Velo'v supply fits especially a demand not satisfied when the public transport station is too distant from home.
\end{abstract}

Keywords: bike-sharing; Lyon; annual membership; discrete choice model; one week travel diary; 


\section{Introduction}

Bike sharing schemes (BSS) in urban areas have sprawled around the world at an accelerated pace over the last years, and could announce unprecedented transformations in contemporary mobility and urban lives. The rapid emergence and policy adoption of these schemes has already been documented in several papers (DeMaio, 2009; Parkes et al, 2013). The success of these schemes and numerous studies already published have provided significant knowledge gains regarding planning, operational management, public policy assessment, modal shift and users attitudes or perceptions (Shaheen et al, 2010; Fishman et al, 2013; Fishman, 2016) but only few regarding analysis of social transformations induced by this new kind of travel mode (apart from Ricci, 2015).

Most of the previous studies performed detailed analysis of anonymous bike flow data, yielding original insights on spatiotemporal patterns and dynamic performance of the systems (Caulfield et al, 2017). This is sometimes combined with some basic sociodemographic data recorded at the time of enrollment for annual subscribers but even these are limited (e.g. gender, age, home postcode, see e.g. Morency et al, 2011; Vogel et al, 2014). Some specific additional surveys targeting scheme members cover perceptions of their own modal shift by respondents (Shaheen et al 2013; Bachand-Marleau et al, 2012; Nikitas et al, 2016) or exceptionally compare BSS members with traditional cyclists (Buck et al, 2013) or with the general population (Fishman et al, 2015).

Moreover very few published studies address the issue of inequality of access to bike sharing scheme, whether because of the social profile of the users or the spatial location of stations. One notable exception stands in the papers on the London Bikesharing Scheme by Ogilvie and Goodman (2012) and Goodman and Cheshire (2013) which give evidence of an overrepresentation of males and individuals coming from affluent neighborhoods.

Furthermore knowledge is still to be elaborated on the way this new travel mode takes part in the daily travel behavior of the individual user, how this mobility behavior is modified and more generally how urban practices are modified. One reason of this lack of knowledge may be that registration data and automatic data recording of bikes movements provide only limited information on the socio-demographic profile of the users and their overall daily mobility.

Since the 1980's the research efforts for better understanding day-to-day variation of travel behavior, i.e. intrapersonal variation, has gathered substantial results showing that there is a significant day-to-day variability in travel/activity behavior (Pas and Koppelman 1986; Hanson and Huff 1982, 1986, 1988; Huff and Hanson, 1986; Jones and Clarke 1988; Pas, 1988; Pas and Sundar, 1995; Buliung et al. 2008; Schönfelder and Axhausen, 2010; Neutens et al., 2012). Schlich and Axhausen (2003) used the Mobidrive six-week travel diary dataset (Axhausen et al. 2002) to study the variability of day-to-day travel behavior. They found that travel behavior is more stable on weekdays than weekend. This accumulated knowledge motivated us to carry on a multiday survey on travel behavior of Velo’v annual members.

In order to gain more information on users and uses of BSS we conducted in 2014 a survey on users of the BSS scheme named Velo'v in Lyon (France). The use of bike for daily mobility is very low in France in general. In Lyon agglomeration after decades of decrease the share of bicycling in daily trips had stabilized under $2 \%$ of total trips (including walk, car 
and public transport). The reversal of tendency occurred recently, probably due to a voluntarist policy including the Velo'v bike sharing scheme which started in 2005 and an effort to develop the cycling network and facilities.

The aim of this paper is twofold. First it is to show whether membership to the bike sharing service is explained by a specific socio-demographic profile or by home spatial proximity to stations. Second it is to analyze whether Velo'v annual members have a different travel behavior when compared with the general population. As such it complements the study by Vogel et al (2014) which by the means of a detailed analysis of Velo'v movements provides a typology of users based on their intensity and spatial and temporal aspects of use, despite limited socio-demographic data.

We analyze with a discrete choice model the socio-demographic and spatial factors affecting the probability of being an annual member of the Velo'v scheme. Then we explore with descriptive statistics their daily travel behavior involving as well Velo'v as other (traditional) modes. When possible this behavior is compared with the latest Household Travel Survey of Lyon (2015).

The remainder of the paper is structured as follows. Section 2 describes the Velo'v scheme and section 3 the methodology of data collection and statistical analysis. Section 4 presents the results and section 5 the discussion while section 6 concludes.

\section{The Velo'v scheme}

The Velo’v scheme has now around 350 stations and 4500 bikes in operation, with approximately 50,000 annual registered members at the time of the survey. It is an open scheme operating with fixed 24/7 docking stations where customers (over 15 years of age) can use a variety of smart cards to retrieve a bike (wearing a helmet is not mandatory). Casual users can register with a credit card on the fly at the dock station for one day or 7 days with a fixed fee of respectively $1.5 €$ and $5 €$. The membership fee for an annual season-ticket amounts to $25 €$ per year with a reduced fee of $15 €$ for those between 15 and 25 years of age. All users then have a free duration use of 30 minutes for each Velo'v renting. An additional fee applies for a greater duration of use within the same renting period, rising from $0.75 €$ to $2 €$ per additional half-hour. By way of comparison with public transport the unit fare amounts to $1.8 €$ (for one hour, any distance), the season-ticket to $60.4 €$ per month in general (but half is refunded by the employer) and $30.2 €$ per month for students.

More than 95\% of the 350 Velo'v stations are settled in the center of the Greater Lyon area, a center that we mark with the two adjacent cities of Lyon (divided into nine districts) and Villeurbanne having a total population of 642,625 in 2012 on $62.42 \mathrm{~km}^{2}$ (see Figure 1). The Greater Lyon area adds 57 towns surrounding Lyon and Villeurbanne and covers an area of $534 \mathrm{~km}^{2}$ with a population of 1,324,637 inhabitants (see Table 1). The settlement of Velo'v stations is the result of an interactive process between the local authority (Greater Lyon) and the service provider (JCDecaux-Cyclocity) involving experience and ad hoc analysis of potential implementations in the various districts.

The current contract is scheduled to end in November 2017. A competitive tender process, which is still ongoing, will designate a new service provider. Specifications for tender include a scheme expansion to surrounding municipalities and the introduction of ebikes. 


\section{Velo'v stations network in 2014}

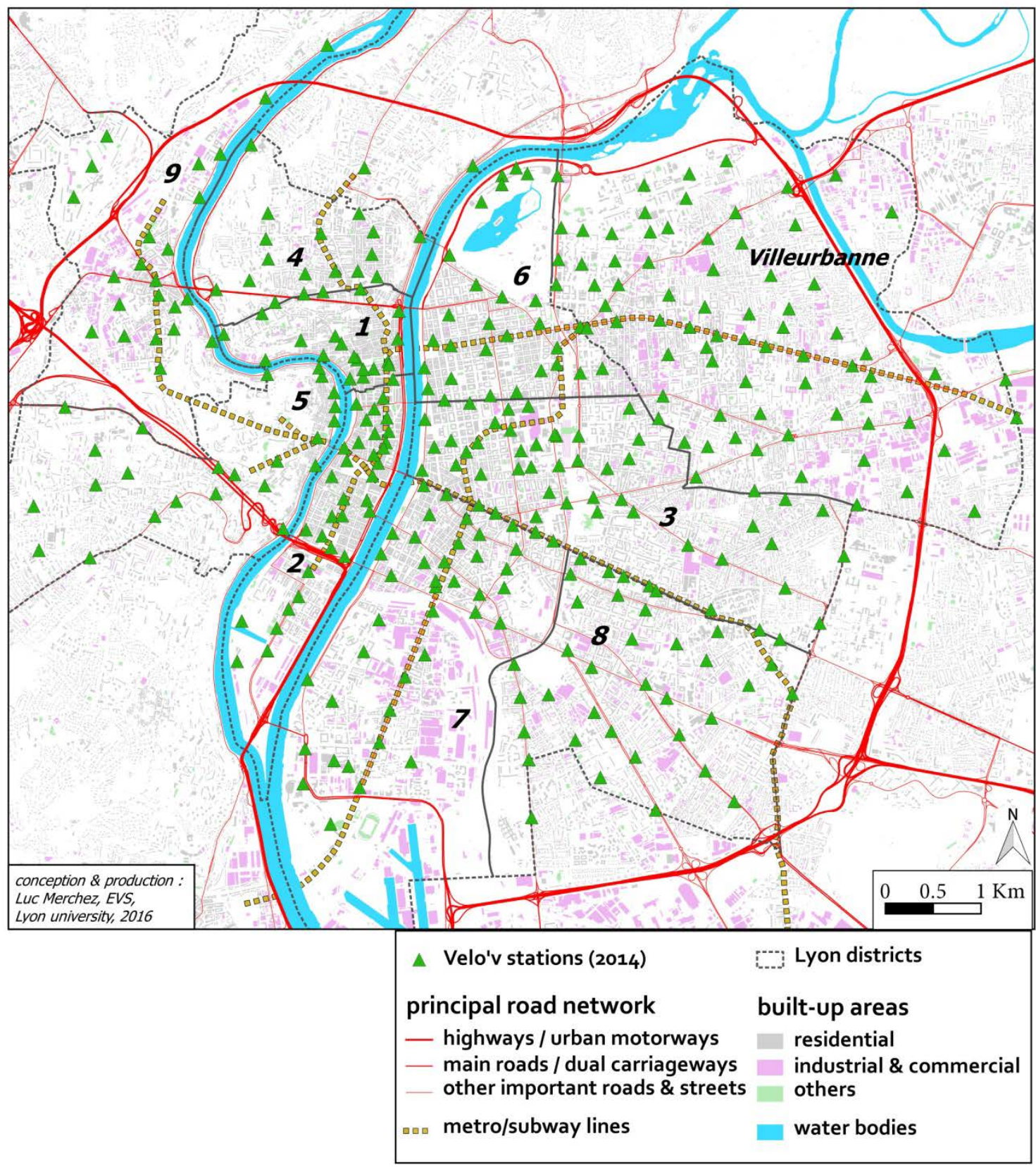

Figure 1: Map of the Velo'v stations

In all what follows we designate with the expression "Velo'v annual members" those who subscribe to the service with a one year period season-ticket. The majority of bike rentals are made by annual members (Vogel et al, 2014): 67\% on average on an everyday 
basis (Monday to Sunday) and more when considering only the weekdays (Monday to Friday). This is why the remainder of the paper focuses on the annual members.

Table 1 shows some basic statistics on the area, including the Velo’v supply.

\begin{tabular}{|c|c|c|c|c|c|c|}
\hline Districts & $\begin{array}{c}\text { Population } \\
2012 * \\
\end{array}$ & Area $\left(\mathrm{km}^{2}\right)$ & $\begin{array}{c}\text { Population } \\
\text { density } \\
\left(\mathrm{hab} / \mathrm{km}^{2}\right) \\
\end{array}$ & $\begin{array}{l}\text { Average annual } \\
\text { income per } \\
\text { household }(€)^{* *}\end{array}$ & $\begin{array}{c}\text { nb Velo’v } \\
\text { stations }\end{array}$ & $\begin{array}{l}\text { Velo'v station } \\
\text { density }\left(/ \mathrm{km}^{2}\right)\end{array}$ \\
\hline Lyon 1 & 29209 & 1.5 & 19344 & 35757 & 18 & 11.9 \\
\hline Lyon 2 & 30958 & 3.4 & 9079 & 47693 & 30 & 8.8 \\
\hline Lyon 3 & 98135 & 6.4 & 15454 & 38770 & 49 & 7.7 \\
\hline Lyon 4 & 36240 & 2.9 & 12369 & 42414 & 18 & 6.1 \\
\hline Lyon 5 & 46693 & 6.2 & 7495 & 39899 & 26 & 4.2 \\
\hline Lyon 6 & 49479 & 3.8 & 13124 & 53251 & 28 & 7.4 \\
\hline Lyon 7 & 75746 & 9.8 & 7769 & 32636 & 39 & 4.0 \\
\hline Lyon 8 & 81454 & 6.7 & 12157 & 30418 & 35 & 5.2 \\
\hline Lyon 9 & 48429 & 7.3 & 6680 & 31331 & 23 & 3.2 \\
\hline Villeurbanne & 146282 & 14.5 & 10075 & 30636 & 73 & 5.0 \\
\hline $\begin{array}{l}\text { Total Lyon- } \\
\text { Villeurbanne }\end{array}$ & 642625 & 62.4 & 10295 & - & 339 & 5.4 \\
\hline $\begin{array}{l}\text { Greater } \\
\text { Lyon }\end{array}$ & 1324637 & 534.0 & 2481 & - & 350 & - \\
\hline
\end{tabular}

*Source : Insee, Recensement de la population 2012

**Source : Insee-DGFiP Revenus fiscaux localisés des ménages

Table 1: General statistics on the area “Lyon-Villeurbanne” and Velo’v supply

The correlations between these indicators (see Table 2) show that: population and area are positively correlated - as expected, but not with population density; population and area are positively correlated with the number of Velo'v stations, which shows that the supply is consistent with the potential demand; the density of Velo'v stations is positively correlated with population density and negatively with the area, which reinforces the consistency of the supply; but there is no significant correlation of Velo'v supply with the indicator of average wealth by district. We will keep in mind this last characteristic in the forthcoming analysis. 


\begin{tabular}{|c|c|c|c|c|c|c|}
\hline Variables & $\begin{array}{c}\text { Population } \\
2012^{*} \\
\end{array}$ & $\begin{array}{c}\text { Area } \\
\left(\mathrm{km}^{2}\right)\end{array}$ & $\begin{array}{c}\text { Population } \\
\text { density }\end{array}$ & $\begin{array}{c}\text { Average annual } \\
\text { income per } \\
\text { household }(€)\end{array}$ & \begin{tabular}{|c} 
nb Velo’v \\
stations \\
\end{tabular} & $\begin{array}{l}\text { Velo’v } \\
\text { station } \\
\text { density }\end{array}$ \\
\hline Population 2012* & 1 & 0.878 & -0.084 & -0.503 & 0.960 & -0.349 \\
\hline Area $\left(\mathrm{km}^{2}\right)$ & & 1 & -0.488 & -0.602 & 0.851 & -0.640 \\
\hline Population density & & & 1 & 0.148 & -0.115 & 0.829 \\
\hline $\begin{array}{l}\text { Average annual income } \\
\text { per household }(€)\end{array}$ & & & & 1 & -0.357 & 0.409 \\
\hline nb Velo’v stations & & & & & 1 & -0.234 \\
\hline Velo’v station density & & & & & & 1 \\
\hline
\end{tabular}

Values in bold are significantly different from zero at 5\% confidence threshold

\section{Table 2: Correlations (Pearson)}

\section{Methodology}

First we present the data collection. Second we set out the statistical methods implemented.

\subsection{Data collection}

As part of the empirical study a specific Internet-based survey was undertaken in September and October 2014 targeted at registered annual members of Velo’v (53,793 annual members who had a valid annual subscription in September 2014). The members were solicited by mailing in the database with an incentive consisting in a lottery for two touchpads. The mailing was driven along the day by day responses with the aim of ending with a sample respecting the distribution of age class, gender, district residence location and length of membership as already known in the database of registered members. So the mailing was random at the beginning and progressively specific groups of members were targeted depending on the quotas to be fulfilled. 25,500 mails were sent and finally 3,161 respondents (i.e. a response rate of $12 \%$ ) fully completed a questionnaire where they described their socio-demographic profile, their travel means and their habits, and recorded a one-day travel diary whether it included a Velo’v trip or not. Moreover nearly 700 volunteers accepted to complete a seven days travel diary (with an additional incentive of $15 €$ for a complete log).

By this way the survey aimed at covering all travel modes (including intermodal uses within the same trip) and day-to-day variations in travel behavior (multimodal uses), beyond the sole use of Velo'v.

The Internet survey went off on the $1^{\text {st }}$ of October 2014 by successive mails sending and was closed on the $20^{\text {th }}$ of October. The weather conditions are an issue regarding bike use (Brandenburg et al, 2007; Miranda-Moreno and Nosal, 2011): during this period the day temperature varied between $10^{\circ}$ and $25^{\circ}$ Celsius with generally a fine or overcast weather except for two days with heavy rainfall (between 50 and $70 \mathrm{~mm}$ per day).

Since the greatest part of Velo'v stations is concentrated in the two cities of Lyon and Villeurbanne we restrict the analysis of the Velo'v sample to those residing in these two cities 
that is to say 2,858 respondents (i.e. $90 \%$ of respondents). As shown in the Appendix (Table 11) there is no significant difference in the socio-demographic profile of this subsample when compared with the overall sample $(\mathrm{N}=3161)$.

As a reference of comparison we use the latest Household Travel Survey available in Lyon urban area which was conducted at the end of 2014 and beginning of 2015 (EMD, 2015). This is a conventional travel survey which records on a representative sample of the inhabitants of the urban area of Lyon, their socio-demographic profile and a one-day travel diary selected among the working days (from Monday to Friday). We restrict the HTS sample to individuals over 15 years of age and living in the two cities of Lyon and Villeurbanne to maintain comparability with our Velo'v survey.

Due to individual privacy issue (legislation in force in France) and the risk of increasing the non-response rate, it was not possible to record the accurate address of Velo'v annual members even if this is known from the Velo'v service provider. We only know if the residence is located in one of the nine districts of Lyon or in the town of Villeurbanne. This is why in the statistical analysis the Velo'v supply is represented by the density of stations per district which is a proxy to the average proximity of individual's residence to a Velo'v station. As we will see even this rough representation is statistically significant in the subsequent model estimation.

A similar privacy issue applies to income which is a sensitive question in French surveys and is known to significantly increase refusals to respond or stopping the questionnaire. This was an issue here since we wanted respondents to carry on with the travel diary. This is why this specific question was avoided.

\subsection{Statistical methods}

The statistical analysis follows two directions, related to the questions set out in the introduction. In the first one we use a discrete choice model to estimate the role of various variables in the probability of enrolling in the Velo'v annual membership. In the second one we use descriptive statistical techniques to compare the mobility behavior of Velo'v annual members to the general population and give an overview of their multimodal travel behavior.

The choice of being annually registered to the Velo'v service is modeled as an utility maximization problem. The model is based on the assumption of utility maximizing behavior by the decision maker $n$ choosing between the various alternatives $j$ (here two: to be registered or not). This utility, which is only known by the individual, is broken down into two parts, a "representative utility" $V$ depending on the attributes of the decision maker and the alternative which are observed by the researcher, and an additional unknown term $\varepsilon$ which is treated as random. Assuming that the $\varepsilon$ values are identically and independently extreme value distributed for all $j$, we obtain the well-known discrete choice logit model (Train, 2009). Here this reduces to a binary logit model.

However there is an issue in our study regarding the sampling of decision makers who choose not to be registered. Due to limited funding it was only possible to perform a survey on Velo'v registered members and not on the general population (those who are not registered). However this population can be addressed thanks to the latest Household Travel Survey available in Lyon area (EMD, 2015). This survey is based on an exogenous representative sampling of the population of residents with a stratification based on the areas of residence location. Statistical weights are attached to each individual in order to represent the population of the geographical strata. We used these weights for comparison of mobility 
indicators between the general population and Velo'v scheme members but not for the discrete choice model.

Our sampling method looks akin a choice based sample which aggregates the sample of respondents stemming from the Velo'v annual membership database (this population represents approximately $8 \%$ of the overall Lyon-Villeurbanne population) and the sample stemming from the HTS 2015. However unfortunately we have no indication of Velo'v membership in the HTS survey. Our working assumption is to assimilate this last sample to those who choose not to be registered to the Velo'v service. However in this sample, 118 individuals stated they have used Velo'v for their trips on the day of the survey. To avoid any ambiguity regarding their potential annual membership these individuals were removed from the HTS sample in the discrete choice modeling.

Strictly speaking, since our overall sampling is different from a conventional exogenous sampling, we should not use the exogenous sampling maximum likelihood estimator conventionally used in logit models. However the literature (Manski and Lerman, 1977; Manski and Mc Fadden, 1981; Cosslett, 1981) shows that this estimator gives consistent estimates of attributes coefficients even in this case. This is not the case for estimates of the alternative specific dummies but they are not at stake in our analysis (and we know the share of annual members in other respects). Thus we used the exogenous sampling maximum likelihood estimator. The estimation has been made thanks to the $\mathrm{R}$ statistical package (R Core Team, 2016) and its package “mlogit” (Croissant, 2013).

\section{$4 \quad$ Results}

\subsection{Basic statistics}

Table 3 shows on the two samples, Velo'v and HTS, the statistics of the variables used in the subsequent analysis. Since the variables stemmed from two different survey questionnaires some matching was required to make them comparable. This was possible for all variables except for level of education.

The choice of the variables shown in Table 3 is guided by preliminary descriptive statistics (not shown here) and some hypotheses. We already found that men are more represented than women in the population of Velo'v users and that these users are younger than the average population, thus we included gender and age. The residential proximity to Velo'v stations is approached through the residential location categorized along the nine districts of Lyon and the city of Villeurbanne.

Another series of hypotheses relates to the potential influence of travel capabilities, through the holding of a driver's license or a public transport season-ticket: is there any link of such capabilities with the probability of being registered to Velo'v?

Finally, a lot of students use Velo'v but also working people, particularly those with higher social position. The "not working" condition is in fact detailed into three conditions: retired, studying, and not working (including jobless, in search of job or not trying to, housewife, etc.). What is the effect of working status and social position on the probability of being registered? In view of this issue we included working status (working, not working, retired, studying) and an indicator of social position through occupational hierarchy: selfemployed, senior management/professional, middle management, clerical staff, laborer, no occupation, studying. 
When compared with the HTS survey, which is by design representative of the general population, the population of Velo'v annual members (of which our sample is representative) is very different. There is an over-representation of people living in $3^{\text {rd }}$ and $7^{\text {th }}$ districts of Lyon, which are known as districts where more people with higher social positions or more young people live. Conversely there is an under-representation of $8^{\text {th }}$ and $9^{\text {th }}$ districts, where more working-class people are living. The proportion of males is higher, as are the holders of a driver's license or a public transport season-ticket. There are also more working people and more students in the Velo'v population. The senior managers / professionals are also over-represented while other occupational positions are underrepresented. Finally the Velo'v population is much younger than the general population. 


\begin{tabular}{|c|c|c|c|c|c|}
\hline & & \multicolumn{2}{|c|}{ Velo’v sample } & \multicolumn{2}{|c|}{ HTS 2015 sample* } \\
\hline & & $\mathrm{N}$ & $\%$ & $\mathrm{~N}$ & $\%$ \\
\hline \multirow[t]{11}{*}{ District of residence } & Lyon 1 & 172 & 6 & 308 & 4 \\
\hline & Lyon 2 & 189 & 7 & 463 & 7 \\
\hline & Lyon 3 & 588 & 21 & 999 & 14 \\
\hline & Lyon 4 & 118 & 4 & 299 & 4 \\
\hline & Lyon 5 & 104 & 4 & 628 & 9 \\
\hline & Lyon 6 & 241 & 8 & 362 & 5 \\
\hline & Lyon 7 & 498 & 17 & 788 & 11 \\
\hline & Lyon 8 & 246 & 9 & 883 & 13 \\
\hline & Lyon 9 & 132 & 5 & 584 & 8 \\
\hline & Villeurbanne & 569 & 20 & 1703 & 24 \\
\hline & Total & 2857 & 100 & 7017 & 100 \\
\hline \multirow[t]{3}{*}{ Gender } & female & 1247 & 44 & 3725 & 53 \\
\hline & male & 1610 & 56 & 3292 & 47 \\
\hline & Total & 2857 & 100 & 7017 & 100 \\
\hline \multirow[t]{3}{*}{ Driver's license } & license_no & 406 & 14 & 1803 & 26 \\
\hline & license_yes & 2451 & 86 & 5214 & 74 \\
\hline & Total & 2857 & 100 & 7017 & 100 \\
\hline \multirow[t]{5}{*}{ Level of education } & 2-secondary & 159 & 6 & na & na \\
\hline & 3-A-level & 458 & 16 & na & na \\
\hline & 4-undergraduate & 403 & 14 & na & na \\
\hline & 5-university degree & 1837 & 64 & na & na \\
\hline & Total & 2857 & 100 & na & na \\
\hline \multirow[t]{5}{*}{ Working status } & 1-working & 1707 & 60 & 3315 & 47 \\
\hline & 2-not working & 186 & 7 & 817 & 12 \\
\hline & 3-retired & 130 & 5 & 1421 & 20 \\
\hline & 4-studying & 834 & 29 & 1464 & 21 \\
\hline & Total & 2857 & 100 & 7017 & 100 \\
\hline \multirow[t]{3}{*}{ PT season ticket } & seasonticket_no & 1476 & 52 & 4140 & 59 \\
\hline & seasonticket_yes & 1381 & 48 & 2877 & 41 \\
\hline & Total & 2857 & 100 & 7017 & 100 \\
\hline \multirow[t]{8}{*}{ Occupational hierarchy } & 2-self-employed & 83 & 3 & 422 & 6 \\
\hline & $\begin{array}{r}\text { 3-senior management / } \\
\text { professional }\end{array}$ & 1134 & 41 & 1435 & 20 \\
\hline & 4-middle management & 250 & 9 & 1299 & 19 \\
\hline & 5-clerical staff & 365 & 13 & 1363 & 19 \\
\hline & 6-laborer & 38 & 1 & 758 & 11 \\
\hline & 7-no occupation & 33 & 1 & 277 & 4 \\
\hline & 8-studying & 868 & 31 & 1463 & 21 \\
\hline & Total & 2771 & 100 & 7017 & 100 \\
\hline \multirow[t]{6}{*}{ Age class } & $1(<30)$ & 1614 & 56 & 2358 & 34 \\
\hline & $2(30-44)$ & 647 & 23 & 1734 & 25 \\
\hline & $3(45-59)$ & 433 & 15 & 1277 & 18 \\
\hline & $4(60-74)$ & 154 & 5 & 1004 & 14 \\
\hline & $5(>74)$ & 9 & 0 & 644 & 9 \\
\hline & Total & 2857 & 100 & 7017 & 100 \\
\hline
\end{tabular}

\footnotetext{
* Inhabitants of Lyon-Villeurbanne, above 15 years of age
}

Table 3: Statistics on the samples of Velo'v annual members and HTS 2015 


\subsection{The probability of being a Velo'v annual member}

Preliminary analyses (not shown here) indicate an effect of the current working status (working or not, retired, studying) but also an effect of socio-economic position through the occupational hierarchy whether currently working or not. This is why a composite variable ("status.occupation") is elaborated, based on interaction between current working status and occupational hierarchy. The hypothesis is that occupational hierarchy (i.e. social position) has an effect on the probability of being registered but this effect can be mediated by the current working status (cf. Table 4).

\begin{tabular}{|l|r|r|}
\hline \multicolumn{1}{|c|}{ status.occupation } & \multicolumn{1}{|c|}{ N } & \multicolumn{1}{|c|}{ \% } \\
\hline working: self-employed & 2168 & 22 \\
\hline working: sr manager/professional & 1049 & 11 \\
\hline working: middle manager & 1072 & 11 \\
\hline working: clerk & 392 & 4 \\
\hline working: labourer & 21 & 0 \\
\hline not working: self-employed & 153 & 2 \\
\hline not working: manager/professional & 126 & 1 \\
\hline not working: middle manager & 222 & 2 \\
\hline not working: clerk & 144 & 1 \\
\hline not working:labourer & 66 & 1 \\
\hline retired: self-employed & 430 & 4 \\
\hline retired: manager/professional & 356 & 4 \\
\hline retired: middle manager & 425 & 4 \\
\hline retired: clerk & 254 & 3 \\
\hline retired: labourer & 321 & 3 \\
\hline no occupation & 2292 & 24 \\
\hline studying & 9682 & 100 \\
\hline Total & & \\
\hline
\end{tabular}

Table 4: Status x occupation of the overall sample (Velo'v + HTS)

Table 5 gives the results of the logit model estimation. Being male increases the probability of being registered, while being older than 30 decreases this probability. The annual members are also significantly more likely to be holders of a season ticket on public transport but also more likely to be holders of a driver's license.

Regarding the effect of supply, the density of stations is significant (and more effective with a logarithm transformation). The direction is positive as expected.

For "status.occupation" the reference is "working: self-employed". Being in the position of middle manager, clerk or laborer, whether currently working or not or even retired, decreases significantly the probability of being registered. Being in the position of a senior manager or a professional currently working or not has no significant effect on the probability of being registered when compared to self-employed people whether working or not. Regarding the other occupations one sees having "no occupation" decreases also the probability of being registered. It is the same for "studying” but to a lesser extent. 


\begin{tabular}{|c|c|c|c|c|c|}
\hline & Estimate & Std. Error & t-value & $\operatorname{Pr}(>|t|)$ & Significance \\
\hline [1] & -1.577 & 0.219 & -7.189 & $6.52 \mathrm{E}-13$ & $* * *$ \\
\hline gender[male] & 0.303 & 0.050 & 6.019 & 1.75E-09 & $* * *$ \\
\hline age.class[2(30-44)] & -0.903 & 0.074 & -12.277 & $<2.2 \mathrm{e}-16$ & $* * *$ \\
\hline age.class[3(459)] & -0.965 & 0.081 & -11.875 & $<2.2 \mathrm{e}-16$ & $* * *$ \\
\hline age.class[4(60-74)] & -1.660 & 0.170 & -9.753 & $<2.2 \mathrm{e}-16$ & $* * *$ \\
\hline age.class $[5(>74)]$ & -3.741 & 0.383 & -9.760 & $<2.2 \mathrm{e}-16$ & $* * *$ \\
\hline license[license_yes] & 0.913 & 0.071 & 12.926 & $<2.2 \mathrm{e}-16$ & $* * *$ \\
\hline season.ticket[seasonticket_yes] & 0.159 & 0.052 & 3.039 & 0.0023724 & ** \\
\hline $\log ($ station.density) & 0.448 & 0.074 & 6.080 & $1.20 \mathrm{E}-09$ & *** \\
\hline $\begin{array}{l}\text { status.occupation[working: sr } \\
\text { manager/professional] }\end{array}$ & 0.226 & 0.161 & 1.405 & 0.1599912 & \\
\hline status.occupation[working: middle manager] & -1.029 & 0.174 & -5.900 & 3.64E-09 & *** \\
\hline status.occupation[working: clerk] & -0.277 & 0.170 & -1.627 & 0.1036512 & \\
\hline status.occupation[working: labourer] & -2.385 & 0.270 & -8.830 & $<2.2 \mathrm{e}-16$ & *** \\
\hline status.occupation[not working: self-employed] & -0.279 & 0.520 & -0.537 & 0.5913269 & \\
\hline $\begin{array}{l}\text { status.occupation[not working: } \\
\text { manager/professional] }\end{array}$ & -0.040 & 0.232 & -0.175 & 0.8614111 & \\
\hline status.occupation[not working: middle manager] & -1.365 & 0.308 & -4.434 & $9.25 \mathrm{E}-06$ & $* * *$ \\
\hline status.occupation[not working: clerk] & -1.324 & 0.263 & -5.039 & 4.67E-07 & $* * *$ \\
\hline status.occupation[not working:labourer] & -2.432 & 0.421 & -5.783 & 7.35E-09 & $* * *$ \\
\hline status.occupation[retired: self-employed] & -0.632 & 0.576 & -1.097 & 0.2728011 & \\
\hline status.occupation[retired: manager/professional] & 0.027 & 0.252 & 0.105 & 0.9161553 & \\
\hline status.occupation[retired: middle manager] & -0.622 & 0.291 & -2.133 & 0.0329077 & * \\
\hline status.occupation[retired: clerk] & -1.475 & 0.366 & -4.030 & 5.58E-05 & *** \\
\hline status.occupation[retired: labourer] & -1.360 & 0.403 & -3.375 & 0.0007392 & *** \\
\hline status.occupation[no occupation] & -0.947 & 0.232 & -4.079 & 4.52E-05 & *** \\
\hline status.occupation[studying] & -0.478 & 0.169 & -2.820 & 0.0048067 & ** \\
\hline \multicolumn{6}{|c|}{ Signif. codes: $0<{ }^{\prime} * *^{\prime}<0.001<^{\prime} * *^{\prime}<0.01<*^{\prime}<0.05<{ }^{\prime} . '<0.1$} \\
\hline \multicolumn{6}{|c|}{$\mathrm{N}=9682$} \\
\hline \multicolumn{6}{|l|}{ Log-Likelihood: -4925.5} \\
\hline \multicolumn{6}{|l|}{ McFadden $\mathrm{R}^{2}: 0.152$} \\
\hline Likelihood ratio test : $\chi^{2}=1766.3$ (p.value $=<2$. & 22e-16) & & & & \\
\hline
\end{tabular}

Table 5: Binary logit model of the probability of being registered to the Velo'v service

\subsection{The travel means and mobility behavior of Velo'v annual members along the week}

Eighty-six percent of annual members living in Lyon-Villeurbanne hold a car driver's license and forty-eight percent of them hold a public transport season-ticket (see Table 3). Moreover, as shown in Table 6, during the working days (Monday to Friday) nearly half of them have access to a car for their sole use $(44 \%+4 \%$, see Table 6$)$. To this add $20 \%$ who can have access to a car some time (but depending on arrangements with relatives) while only 
$31 \%$ of annual members state they have no access to a private car at all. This means that the majority of them are not captive of public transport.

\begin{tabular}{|l|r|}
\hline I have a car for my sole use & $44 \%$ \\
\hline I have a company car & $4 \%$ \\
\hline I can have a car (shared with my relatives) & $20 \%$ \\
\hline I have no car & $31 \%$ \\
\hline other & $1 \%$ \\
\hline Total & $100 \%$ \\
\hline
\end{tabular}

Table 6: Availability of a private car during the working days (Velo'v annual members)

We turn now to day-to-day travel behavior of Velo'v annual members. A sample of volunteers have recorded their daily mobility during one week in order to give an overview of their day-to-day mobility. This week diary allows an analysis of variability of behavior from day to day and especially of "multimodality" that is to say the use of various travel modes during the week. 671 Velo'v annual members have completed a full 7-days diary. From this diary we exclude Saturdays and Sundays which show as expected very different travel behaviors with in general no mandatory activities like work or university. Thus we stick to classical working days (Monday to Friday). Moreover this allows comparison, when possible, with the Household Travel Survey in 2015 which recorded travel behavior of Lyon's inhabitants only on one day per individual between Monday and Friday.

Table 11 in the appendix gives the socio-demographic statistics on the Velo'v sample of annual members $(\mathrm{N}=3161)$, those residing in Lyon and Villeurbanne $(\mathrm{N}=2857)$, the subsample of those having filled up the 7-days diary $(\mathrm{N}=671)$ and the subsample of those latter residing in Lyon and Villeurbanne $(\mathrm{N}=601)$. The inspection of this table shows that there is no significant difference in profile between these samples except for a higher share of women in those respondents having filled up the 7-days diary (51-52\% vs $43-44 \%$ ) and a slightly higher share of those respondents holding a public transport season-ticket (51-53\% vs 48-50\%).

Firstly we analyze the use of travel modes by Velo’v annual members for their trips. We use the conventional definition of a trip which is a switch from one activity (which is not travel) to another with a change of location. For this we elaborated five categories of "main travel mode" with the aim of representing: exclusive use of one mode during the whole trip when it is the case (whether walk, the car or public transport); making public transport stand out when it is used in combination with the car (as passenger or driver); and making also Velo'v mode stand out. The series of rules are as follows. First we put together some modes: bus, tramway, metro and regional train are all considered as the same mode designated as "public transport" (PT); "car as a passenger" and "car as a driver" are put together as "car". Then "walk" mode is the main mode when the entire trip is performed by foot otherwise when walk is combined with at least one mechanized mode this last mode is the main mode. When only one mechanized mode is used (even with connections) this is the main mode. When Velo'v is used in combination with another mode (such as PT or the car) then "Velo'v" is designated as the main mode. When PT is used in combination with another mode (such as the car) then "PT" is designated as the main mode. Other combinations are attributed to 
"other": this includes motorized two-wheels, private bikes (recall that trips with a private bike represent about $2 \%$ of trips in the general population) and odd combinations. The same rules were applied to HTS 2015 based on our own data processing.

A first approach consists in summing up all the trips performed from Monday to Friday by Velo'v members, computing the aggregated shares of travel modes and purposes and comparing these to those of the HTS. For a strict comparison we restrict the Velo'v sample to the 601 individuals living in Lyon and Villeurbanne. As shown in Table 7, those Velo'v annual members perform on average a little fewer trips per day than the general population (inhabitants of Lyon-Villeurbanne, above 15 years of age) in 2015: 3.3 trips per day vs 3.4. Regarding the main travel modes Velo'v annual members use Velo'v for only $22 \%$ of their trips over a five working days period: this is a first indication that Velo'v is for them only one mode among others and not the main or preferred one (recall that there were only two days of heavy rainfall during the three weeks of recording). Moreover, among these $22 \%$ of Velo'v trips, $86 \%$ are made with Velo'v alone and $14 \%$ are combined with another mode, essentially public transport, giving an overall share of $3 \%$ for the combination Velo'v+PT. When it comes to trips not involving Velo'v, the Velo'v members use more public transport (PT, 30\%) than the general population in 2015 (27\%) but far less walking mode ( $24 \%$ vs $42 \%)$ and car (15\% vs $27 \%)$. These two last modes are partly replaced by Velo'v.

The same Table 7 shows the distribution of trips according to purpose at destination. Velo'v annual members commute more to work than the general population in 2015 (31\% vs $21 \%)$ and at the same level to study (11\%). On the opposite they travel less for shopping or personal matters, and dropping or picking someone else. Moreover if we restrict the distribution of trips per purpose to those made with Velo'v mode during the week, we see that there is no significant difference with the distribution of trips per purpose when all modes are considered, apart from a higher share of commuting to work with Velo'v (36\% vs $31 \%)$. This confirms that regarding commuting Velo’v is used as every other travel mode. 


\begin{tabular}{|c|c|c|c|}
\hline & \multicolumn{2}{|c|}{ Velo’v survey } & HTS 2015 survey* \\
\hline Trips per main travel mode & Trips/Mo-Fri (nb) & $\%$ & \\
\hline Walk & 2434 & $24 \%$ & $42 \%$ \\
\hline Velo’v & 2176 & $22 \%$ & na \\
\hline PT & 2972 & $30 \%$ & $27 \%$ \\
\hline Car & 1479 & $15 \%$ & $27 \%$ \\
\hline Other & 905 & $9 \%$ & $4 \%$ \\
\hline Total & 9966 & $100 \%$ & $100 \%$ \\
\hline $\mathrm{Nb}$ individuals & 601 & & 528,319 \\
\hline average period Mo-Fri & 16.6 & & na \\
\hline \multirow[t]{2}{*}{ average daily } & 3.3 & & 3.4 \\
\hline & \multicolumn{2}{|c|}{ Velo’v survey } & HTS 2015 survey* \\
\hline Trips per purpose (Mo-Fri) & Mo-Fri all modes & Mo-Fri Velo’v & \\
\hline Home <--> Work & $31 \%$ & $36 \%$ & $21 \%$ \\
\hline Home <--> Study & $11 \%$ & $11 \%$ & $11 \%$ \\
\hline Home <--> Leisure & $16 \%$ & $18 \%$ & $17 \%$ \\
\hline Home <--> Shopping/Personal & $12 \%$ & $12 \%$ & $20 \%$ \\
\hline Home <--> Dropping/Picking & $3 \%$ & $2 \%$ & $9 \%$ \\
\hline Home <--> Other & $0 \%$ & $0 \%$ & $1 \%$ \\
\hline not linked to Home & $26 \%$ & $20 \%$ & $22 \%$ \\
\hline Total & $100 \%$ & $100 \%$ & $100 \%$ \\
\hline
\end{tabular}

* Inhabitants of Lyon-Villeurbanne, above 15 years of age, with statistical weights

\section{Table 7: Mobility indicators for Velo'v annual members from Monday to Friday}

A second approach consists in going further into the multimodal behavior of Velo'v members along the week, by the means of multivariate analysis. For each individual we compute the number of times (trips) each of the five main travel modes was used during the five working days. Thus we obtain a table of 671 observations and five columns, accounting for the intensity of use of the five modes during the week by each individual (the comparison with the HTS is not possible anymore since this last survey is a one-day per individual survey).

Table 8 gives a summary for each travel mode and shows that each one is used by a majority of the sample except for the mode "other" (only 25\%). This is why we exclude this travel mode from the following analysis. 


\begin{tabular}{|c|c|c|c|c|c|c|}
\hline & Walk & Velo’v & PT & Car & Other & Total \\
\hline Minimum & 0 & 0 & 0 & 0 & 0 & 2 \\
\hline Maximum & 24 & 19 & 33 & 28 & 33 & 39 \\
\hline 1st Quartile & 0 & 0 & 0 & 0 & 0 & 12 \\
\hline Median & 2 & 2 & 3 & 1 & 0 & 16 \\
\hline 3rd Quartile & 6 & 6 & 8 & 4 & 1 & 20 \\
\hline Mean & 3.781 & 3.557 & 4.885 & 2.775 & 1.480 & 16.478 \\
\hline Variance (n-1) & 19.980 & 16.232 & 26.087 & 18.163 & 14.835 & 38.095 \\
\hline Standard deviation (n-1) & 4.470 & 4.029 & 5.108 & 4.262 & 3.852 & 6.172 \\
\hline \% zero & 31 & 30 & 26 & 45 & 75 & 0 \\
\hline
\end{tabular}

Table 8: Individual use of travel modes during the Monday-Friday period ( $\mathrm{N}=671)$

Then we seek to cluster the individuals characterized each by their vector of four travel mode intensity (number of trips by walk, Velo'v, public transport and car) by the means of an R kmeans procedure using the Hartigan and Wong algorithm (1979). In order to avoid the influence of different variances between variables data are scaled. First we look for the optimal number of clusters, trading-off between the number of clusters and the overall quality of clustering (ratio between sum of squares and total sum of squares) and choose a target of 5 clusters. After iteration an overall quality of $65 \%$ of total sum of squares is obtained.

Table 9 and Figure 2 illustrate the use of travel modes within each of the five clusters. They show that cluster 2 ("LowMob") differs from the others by its low level of overall mobility (9.1 trips on average over the whole 5-days period) while the four other clusters are over 15 trips on average. These four clusters have in common that in each of them one travel mode dominates the others (but it is not exclusive). This is why we can name each of these clusters with their dominant travel mode, respectively "Velo’v", "Walk”, "PT" and "Car".

\begin{tabular}{|r|r|r|r|r|r|r|}
\hline Cluster & Walk & Velo'v & PT & Car & Total & $\mathrm{N}$ \\
\hline 1 & 3.0 & 10.5 & 1.5 & 1.0 & 16.0 & 115 \\
\hline 2 & 2.0 & 2.5 & 2.8 & 1.9 & 9.1 & 208 \\
\hline 3 & 12.8 & 2.9 & 3.3 & 1.4 & 20.3 & 90 \\
\hline 4 & 2.4 & 1.4 & 11.9 & 1.3 & 17.0 & 173 \\
\hline 5 & 2.4 & 1.9 & 2.0 & 12.0 & 18.3 & 85 \\
\hline & & & & & Total & 671 \\
\hline
\end{tabular}

Table 9: Average number of trips per travel mode performed by the individuals in the five clusters 


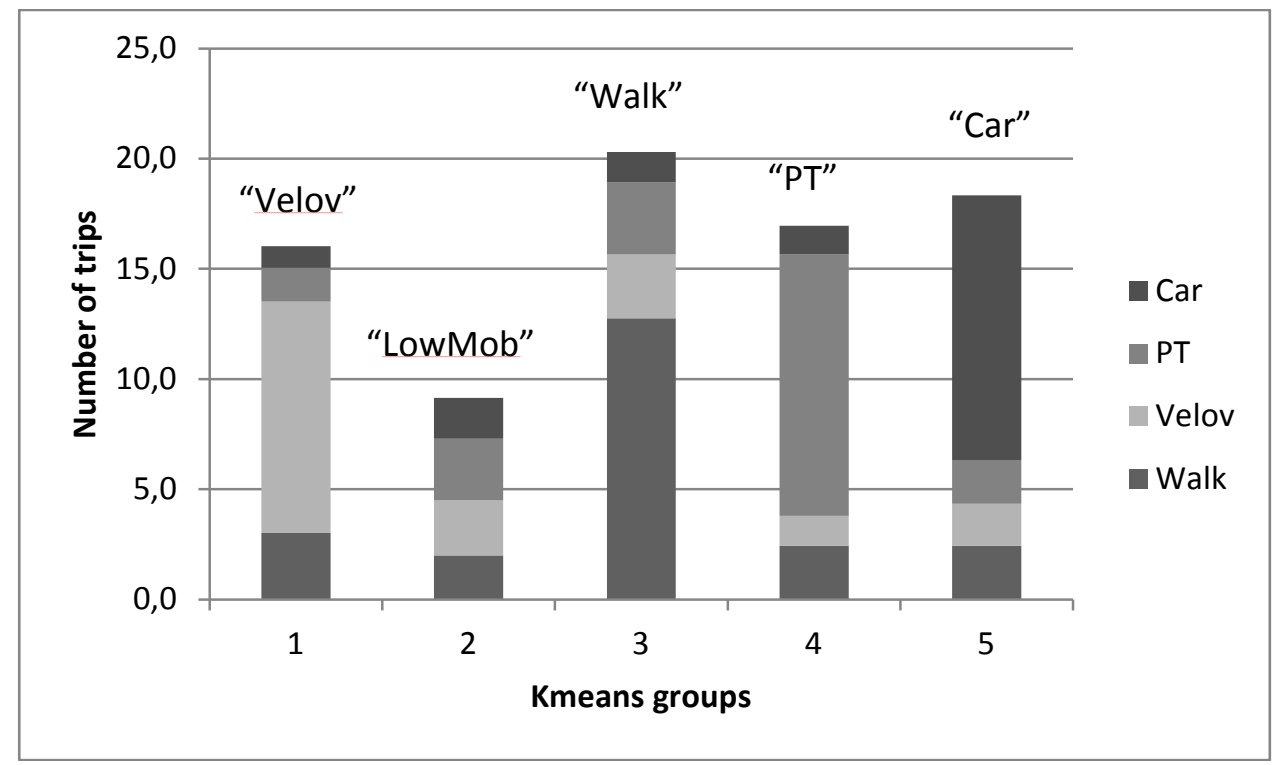

Figure 2: Share of travel modes in the five clusters

Then we seek to characterize the individuals belonging to each of these clusters. We presume that socio-economic attributes such as age, gender and occupation, or spatial attributes such as residential location may give further insights on the interpretation of these clusters.

Figure 3 shows a boxplot of age (as a continuous variable) in each of the five clusters. This indicates that age is not discriminating the individuals between the clusters except for the fifth one characterized by a dominant use of car. Older individuals have a higher probability to belong to this "Car" cluster. 


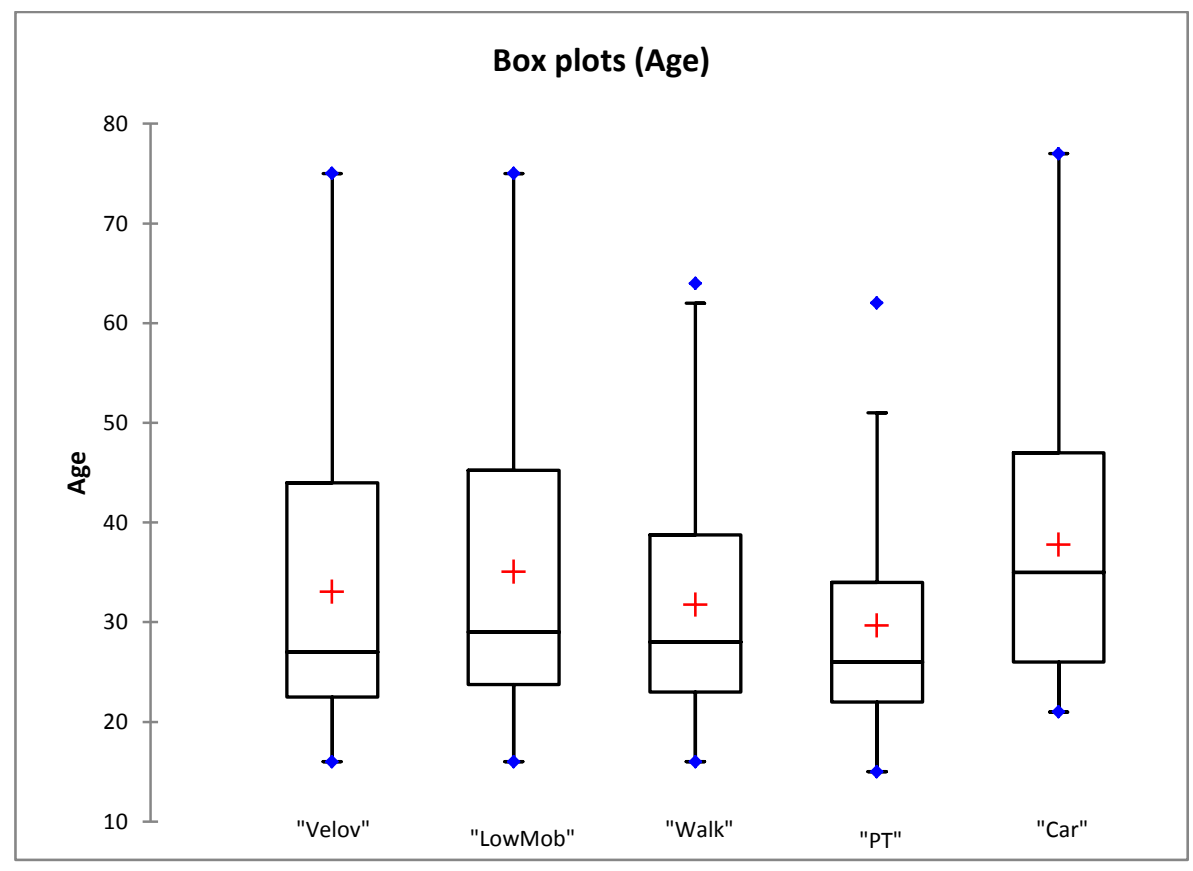

Figure 3: Boxplots of age in the five clusters

Regarding the other attributes which are nominal in nature a Chi2 statistical test is performed on each contingency table between the attribute and the cluster membership (e.g. gender $\mathrm{x}$ cluster): this is in order to keep only attributes where the Chi2 statistics allow rejection of the null hypothesis of independence between the attribute and the cluster membership. Then the Fisher's exact test is used to investigate the effect of each of attribute's category (since the cell size may be small).

Regarding the link between attributes and cluster membership, gender, working status, residential location and distance from home to the nearest main public transport station (subway or tramway) are all significantly linked to cluster membership while this is not the case for job occupation.

Table 10 below indicates for each nominal category whether it has a significant link (Fishers' exact test, significance at the 5\% level) with cluster membership, either positively (+; higher proportion of membership), negatively (-; lower proportion of membership) or not significant.

Gender female is negatively linked to "Velo'v" and "LowMob” cluster membership, and positively to "PT" and "Car" clusters. This is the opposite for males. Being a student is positively linked to "Velo'v" and "PT" clusters, negatively to "Car" and "LowMob" clusters. Being at work is positively linked to "Car" cluster while those not working (apart from students) are positively linked to "LowMob" cluster and negatively to "PT" one.

The effect of home location is analyzed through two variables. The variable "home location inside/outside LV" is a proxy for density, which is on average higher inside the two towns of Lyon and Villeurbanne (LV) which delimit the agglomeration center and the supply of Velo'v stations. One expects a link with “Velo'v" cluster but this is not the case (because this is a too rough representation of spatial proximity to Velo'v stations). However home location inside Lyon-Villeurbanne is positively linked to "Walk" cluster and negatively to 
"Car" cluster. This is the opposite for home location outside Lyon-Villeurbanne. The second variable reflects the walking distance from home to the nearest main public transport station (subway or tramway) expressed in minutes by the respondent itself. A distance less than 5 minutes from a PT station is positively linked with the "PT" cluster as expected and negatively with the "Car" one. On the opposite when at distance farther than 20 minutes there is a positive link with the "Car" cluster and a negative one with the "Velo'v" cluster". At intermediate distance (between 10 and 20 minutes), there is a positive link with the "Velo'v" cluster.

\begin{tabular}{|c|c|c|c|c|c|}
\hline Clusters: & “Velo’v” & "Walk" & “PT” & “Car” & “LowMob” \\
\hline \multicolumn{6}{|c|}{ Gender } \\
\hline Female & - & & + & + & - \\
\hline Male & + & & - & - & + \\
\hline \multicolumn{6}{|c|}{ Working status } \\
\hline Student & + & & + & - & - \\
\hline Working & & & & + & \\
\hline Non working & & & - & & + \\
\hline \multicolumn{6}{|c|}{ Home location } \\
\hline Inside LV & & + & & - & \\
\hline Outside LV & & - & & + & \\
\hline \multicolumn{6}{|c|}{ Walking distance from home to PT station (subway or tramway) } \\
\hline Less than 5 min & & & + & - & \\
\hline \multicolumn{6}{|l|}{ Between 5 and 10 min } \\
\hline Between 10 and 20 min & + & - & - & & \\
\hline More than 20 min & - & & & + & \\
\hline No station nearby & & - & & + & \\
\hline
\end{tabular}

Table 10: Links between individual attributes and cluster membership 


\section{Discussion}

The analysis of the profile of Velo'v annual members shows that they are in majority male, under 30 years of age, holders of a public transport season-ticket and a car driving license. Moreover, rather than being students they are working on higher social positions such as self-employed, senior managers or professionals, opposite to middle managers, employees or workers.

This younger age profile is also observed in Montreal Bixi scheme (Morency et al, 2011) or in Washington Capital Bikeshare scheme (Buck et al, 2013). The predominance of individuals with higher social positions is in line with the observations of Ogilvie and Goodman (2012) in London.

A question then arises whether the individual registers to the service because of either her higher social position or her residential location next to a bike-share station, or even because stations are rather located in wealthy areas.

Our results can give at least some answers to this question. Firstly the proximity to stations has a significant positive effect on the probability to register to the service, a finding which is line with that of Bachand-Marleau et al (2012) for Bixi Montreal and Fishman et al (2015) in the case of Brisbane and Melbourne. Goodman and Cheshire (2013) found the same in the case of London but also that the extension of the scheme to deprived areas has increased the use of bike-sharing by their residents. Secondly, as shown previously the Velo'v station density per district is not correlated with the average wealth of Lyon's districts. From this we can reasonably conclude that the individual and the spatial effects can be separated. An individual higher social position and the residential proximity to stations have both positive and separate effects on the probability of being an annual member of the service.

When it comes to travel means and behavior, we see that Velo'v annual members are not captive from public transport even if they hold a PT season ticket in higher proportion compared to the general population. The majority of them hold a car driver's license and furthermore nearly half of them have a car for their sole use, not counting those who can get access to a private car some time on working days.

In their day-to-day travel behavior Velo'v is one travel mode among others, not necessarily the preferred one. When comparing Velo'v annual members to the general population both Velo'v and public transport appear on average as substitutes to car or walk. Considering travel purpose, Velo'v is used as any other travel mode, and even in a higher proportion for commuting. This is an indication that for Velo'v annual members Velo'v has become a feature of everyday life.

However, even if Velo'v annual members use the panoply of travel modes and not exclusively Velo'v during the week, they have a dominant travel mode if we consider the result of clustering. Apart from one cluster (31\%) which is "multimodal" but with a low mobility (less than two trips per day on average), the four other clusters gather $69 \%$ of the sample $(\mathrm{N}=671)$ and each of these clusters favors one travel mode, either walk, Velo'v, public transport or the car. When it comes to the social profile of clusters' members, one can associate the car travel mode with older people, males with Velo'v, females with public transport and the car, students with Velo’v and public transport, and working people with the car. 
There is an apparent contradiction regarding students between the results about membership - being a student has a negative low but significant effect on annual membership when compared to the reference status (self-employed) - and the result about mode use students who are registered members favor the use of Velo'v and public transport. These two results refer indeed to two different decisions which are partly independent: the decision to enroll as an annual member and when enrolled the decision to effectively use Velo'v in daily mobility. On average students perform more Velo'v trips (4.03 in the period Mo-Fri) when compared to Velo'v members who are working (3.35).

When it comes to spatial dimension, the distance from home to the nearest subway or tramway station gives a clear indication of mode choice and especially Velo'v which is favored when living between 10 and 20 minutes from a public transport station.

The use of Velo'v as a substitute to other travel modes can be explained by the specific travel conditions within the center of Lyon agglomeration. Velo'v (like private bikes) can be an effective substitute to the car at peak hours since the door-to-door travel times are comparable (Jensen et al, 2010). Velo'v can also be a complement to public transport for the "last mile", when living more than 10 minutes from a public transport station or when the service stops at night. It can also be a substitute to public transport under acceptable weather conditions, because of the low cost of the Velo'v service.

A limitation of our study is that, while the HTS is an official face-to-face survey performed at home by public agents, we cannot exclude the fact that respondents to our own Internet survey may have auto-selected themselves according to unknown attributes. The response rate $(12 \%)$ may look very low. As for other web-based surveys our mailings may have been ignored or being blocked by anti-spam filters. Individuals may have several email addresses (one of which given at the time of registration to the Velo'v service) and only read some of them occasionally. No reminder emails were sent as the BSS operator (JCDecaux) has a policy to keep their email relationship with their members at a low (acceptable) level. Moreover the questionnaire took at least 10 minutes to fill with several screens, which may incite people to quit before achieving it. However, we think that the monitoring of the email solicitation process with quotas representing the total population of annual members (based on age, gender, and residential location which are known at the time of registration) has limited this potential bias.

\section{Conclusion}

To sum up, even if Velo'v is for its members a travel opportunity in everyday life as any other travel mode, it would convey a picture of a mobility service attached to higher social positions when opposed to other positions. On the other hand the proximity to stations has a positive effect on membership and it is encouraging for public policy aiming at reducing inequality of access to the mobility services, here by extending the scheme to the less affluent areas.

However the distortion towards higher social positions gives evidence that this spatial proximity does not do everything for joining the service. Given the low cost of the annual membership in Lyon, one can presume a kind of social or psychological barrier hindering access to the service (which involves using the Internet and holding a credit card). One future research direction would be to check this presumption. 
One of the main perspectives of this research would be to compare these findings with other cities with bike sharing schemes where data on socio-demographic profiles and multiday travel behavior would be available. Does the social specificity of the BSS observed in Lyon (or in London) occur in other cities?

\section{Acknowledgements}

This work was supported by the French "Agence Nationale de la Recherche” [Grant ANR12-SOIN-0001]. We thank our colleagues Bruno Faivre d'Arcier and Nicolas Ovtracht for their contribution to the elaboration of the questionnaire, Luc Merchez for his help, and the operator JCDecaux-CycloCity for their support. We also thank seminar participants at hEART 2015 Conference (Copenhagen, 9-11 September 2015), 95 ${ }^{\text {th }}$ Transportation Research Board Annual meeting (Washington, 10-14 January 2016) and $14^{\text {th }}$ World Conference on Transport Research (Shanghai, 10-15 July 2016).

\section{Appendix}

\begin{tabular}{|c|c|c|c|c|c|c|c|c|c|}
\hline & & \multicolumn{2}{|c|}{$\begin{array}{l}\text { Velo’v } \\
\text { overall }\end{array}$} & \multicolumn{2}{|c|}{$\begin{array}{c}\text { Velo’v } \\
\text { Lyon- } \\
\text { Villeurb. }\end{array}$} & \multicolumn{2}{|c|}{$\begin{array}{c}\text { Velo’v } \\
\text { week diary } \\
\text { overall }\end{array}$} & \multicolumn{2}{|c|}{$\begin{array}{c}\text { Velo’v } \\
\text { week diary } \\
\text { Lyon- } \\
\text { Villeurb. }\end{array}$} \\
\hline & & $\mathrm{N}$ & $\%$ & $\mathrm{~N}$ & $\%$ & $\mathrm{~N}$ & $\%$ & $\mathrm{~N}$ & $\%$ \\
\hline \multirow[t]{12}{*}{ District of residence } & Lyon 1 & 172 & 5 & 172 & 6 & 26 & 4 & 26 & 4 \\
\hline & Lyon 2 & 189 & 6 & 189 & 7 & 29 & 4 & 29 & 5 \\
\hline & Lyon 3 & 588 & 19 & 588 & 21 & 140 & 21 & 140 & 23 \\
\hline & Lyon 4 & 118 & 4 & 118 & 4 & 20 & 3 & 20 & 3 \\
\hline & Lyon 5 & 104 & 3 & 104 & 4 & 15 & 2 & 15 & 2 \\
\hline & Lyon 6 & 241 & 8 & 241 & 8 & 46 & 7 & 46 & 8 \\
\hline & Lyon 7 & 498 & 16 & 498 & 17 & 114 & 17 & 114 & 19 \\
\hline & Lyon 8 & 246 & 8 & 246 & 9 & 60 & 9 & 60 & 10 \\
\hline & Lyon 9 & 132 & 4 & 132 & 5 & 27 & 4 & 27 & 4 \\
\hline & Villeurbanne & 569 & 18 & 569 & 20 & 124 & 18 & 124 & 21 \\
\hline & Other & 304 & 10 & - & - & 70 & 10 & - & - \\
\hline & Total & 3161 & 100 & 2857 & 100 & 671 & 100 & 601 & 100 \\
\hline \multirow[t]{3}{*}{ Gender } & female & 1366 & 43 & 1247 & 44 & 344 & 51 & 312 & 52 \\
\hline & male & 1795 & 57 & 1610 & 56 & 327 & 49 & 289 & 48 \\
\hline & Total & 3161 & 100 & 2857 & 100 & 671 & 100 & 601 & 100 \\
\hline \multirow[t]{3}{*}{ Driver's license } & license_no & 465 & 15 & 406 & 14 & 108 & 16 & 93 & 15 \\
\hline & license_yes & 2696 & 85 & 2451 & 86 & 563 & 84 & 508 & 85 \\
\hline & Total & 3161 & 100 & 2857 & 100 & 671 & 100 & 601 & 100 \\
\hline \multirow[t]{3}{*}{ Level of education } & 2-secondary & 188 & 6 & 159 & 6 & 53 & 8 & 43 & 7 \\
\hline & 3-A-level & 519 & 16 & 458 & 16 & 103 & 15 & 85 & 14 \\
\hline & 4-undergraduate & 464 & 15 & 403 & 14 & 101 & 15 & 90 & 15 \\
\hline
\end{tabular}




\begin{tabular}{|c|c|c|c|c|c|c|c|c|c|}
\hline & 5-university degree & 1990 & 63 & 1837 & 64 & 414 & 62 & 383 & 64 \\
\hline & Total & 3161 & 100 & 2857 & 100 & 671 & 100 & 601 & 100 \\
\hline \multirow[t]{5}{*}{ Working status } & 1-working & 1906 & 60 & 1707 & 60 & 425 & 63 & 378 & 63 \\
\hline & 2-not working & 206 & 7 & 186 & 7 & 40 & 6 & 35 & 6 \\
\hline & 3-retired & 144 & 5 & 130 & 5 & 23 & 3 & 22 & 4 \\
\hline & 4-studying & 905 & 29 & 834 & 29 & 183 & 27 & 166 & 28 \\
\hline & Total & 3161 & 100 & 2857 & 100 & 671 & 100 & 601 & 100 \\
\hline \multirow[t]{3}{*}{ PT season ticket } & seasonticket_no & 1584 & 50 & 1476 & 52 & 314 & 47 & 293 & 49 \\
\hline & seasonticket_yes & 1577 & 50 & 1381 & 48 & 357 & 53 & 308 & 51 \\
\hline & Total & 3161 & 100 & 2857 & 100 & 671 & 100 & 601 & 100 \\
\hline \multirow[t]{8}{*}{ Occupational hierarchy } & 2-self-employed & 89 & 3 & 83 & 3 & 6 & 1 & 5 & 1 \\
\hline & $\begin{array}{r}\text { 3-senior management / } \\
\text { professional }\end{array}$ & 1248 & 39 & 1134 & 41 & 267 & 40 & 244 & 41 \\
\hline & 4-middle management & 295 & 9 & 250 & 9 & 70 & 10 & 58 & 10 \\
\hline & 5-clerical staff & 410 & 13 & 365 & 13 & 102 & 15 & 91 & 15 \\
\hline & 6-laborer & 45 & 1 & 38 & 1 & 8 & 1 & 6 & 1 \\
\hline & 7-no occupation & 38 & 1 & 33 & 1 & 9 & 1 & 8 & 1 \\
\hline & 8-studying & 1036 & 33 & 868 & 31 & 209 & 31 & 189 & 31 \\
\hline & Total & 3161 & 100 & 2771 & 100 & 671 & 100 & 601 & 100 \\
\hline \multirow[t]{6}{*}{ Age class } & $1(<30)$ & 1736 & 55 & 1614 & 56 & 365 & 54 & 332 & 55 \\
\hline & $2(30-44)$ & 725 & 23 & 647 & 23 & 158 & 24 & 140 & 23 \\
\hline & $3(45-59)$ & 516 & 16 & 433 & 15 & 111 & 17 & 95 & 16 \\
\hline & $4(60-74)$ & 174 & 6 & 154 & 5 & 34 & 5 & 31 & 5 \\
\hline & $5(>74)$ & 10 & 0 & 9 & 0 & 3 & 0 & 3 & 0 \\
\hline & Total & 3161 & 100 & 2857 & 100 & 671 & 100 & 601 & 100 \\
\hline
\end{tabular}

Table 11: Socio-demographic profiles of the various Velo'v samples

\section{References}

Axhausen, K.W., Zimmermann, A., Schönfelder, S., Rindsfüser, G., and Haupt, T. (2002) Observing the rhythms of daily life: a six-week travel diary, Transportation, 29(2), 95-124.

Bachand-Marleau, J., Lee, B., El-Geneidy, A. (2012) Better Understanding of Factors Influencing Likelihood of Using Shared Bicycle Systems and Frequency of Use. Transportation Research Record 2314, pp. 66-71.

Brandenburg, C., Matzarakis, A., \& Arnberger, A. (2007). Weather and cycling-a first approach to the effects of weather conditions on cycling. Meteorological applications, 14(1), 61-67.

Buck, D., Buehler, R., Borecki, N., Chung, P., Happ, P., Rawls, B. (2013) Are bikeshare users different from regular cyclists? A first look at short-term users, annual members, and area cyclists in the Washington, DC Region. Transportation Research Board 92nd Annual Meeting. 
Buliung, R.N., Roorda, M.J. and Remmel, T.K. (2008) Exploring spatial variety in patterns of activity-travel behavior: initial results from the Toronto Travel-Activity Panel Survey (TTAPS). Transportation, 35(6), 697-722.

Caulfield, B., O'Mahony, M., Brazil, W., Weldon, P. (2017). Examining usage patterns of a bike-sharing scheme in a medium sized city. Transportation Research Part A: Policy and Practice, 100, 152-161.

Cosslett, S.R. (1981) Efficient Estimation of Discrete Choice Models, in Manski, C.F., Mc Fadden, D.L., Structural Analysis of Discrete Data and Econometric Applications, The MIT Press, pp. 51-111

Croissant, Y. (2013) mlogit: multinomial logit model. $\mathrm{R}$ package version 0.2-4. http://CRAN.R-project.org/package=mlogit

DeMaio, P. (2009) Bike sharing: history, impacts, models of provision, and future. Journal of Public Transportation 12 (4), 41-56.

EMD, 2015. Enquête ménages déplacements (EMD), Lyon / Aire métropolitaine lyonnaise 2015, CEREMA [producteur], ADISP-CMH [diffuseur]

Fishman, E., Washington, S., Haworth, N. (2013) Bike share: a synthesis of the literature. Transport Reviews, 33:2, 148-165.

Fishman, E., Washington S., Haworth, N., Watson, A. (2015) Factors influencing bike share membership: An analysis of Melbourne and Brisbane. Transportation Research Part A 71 17-30.

Fishman, E. (2016). Bikeshare: A review of recent literature. Transport Reviews, 36(1), 92113.

Goodman, A. , Cheshire, J. (2014) Inequalities in the London bicycle sharing system revisited: impacts of extending the scheme to poorer areas but then doubling prices. Journal of Transport Geography 41 (2014) 272-279

Hanson, S. and Huff, J.O. (1982) Assessing day-to-day variability in complex travel patterns, Transportation Research Record, 891, 18-24.

Hanson, S. and Huff, J.O. (1986) Classification issues in the analysis of complex travel behavior, Transportation, 13(4), 273-291.

Hanson, S. and Huff, J.O. (1988) Systematic variability in repetitious travel. Transportation, $15,111-135$.

Hartigan, J. A., Wong, M. A. (1979) A K-means clustering algorithm. Applied Statistics 28, 100-108.

Heinen E., van Wee B., Maat, K. (2010) Commuting by bicycle: An overview of the literature. Transport Reviews, 30/1, p. 59-96.

Huff, J.O., Hanson, S. (1986) Repetition and variability in urban travel. Geographical Analysis 18, 97-114.

Jensen, P., Rouquier, J.B., Ovtracht, N., Robardet, C. (2010) Characterizing the speed and paths of shared bicycle use in Lyon. Transportation Research Part D: Transport and Environment, 15 (2010) 522-524.

Jones, P. and Clarke, M. (1988) The significance and measurement of variability in travel behavior. Transportation 15, 65-87.

Manski, C.F., Lerman, S.R. (1977) The Estimation of Choice Probabilities from Choice Based Samples, Econometrica, 45:8, 1977-1988. 
Manski, C.F., Mc Fadden, D.L. (1981) Alternative Estimators and Sample Designs for Discrete Choice Analysis, in Manski, C.F., Mc Fadden, D.L., Structural Analysis of Discrete Data and Econometric Applications, The MIT Press, pp. 2-50.

Miranda-Moreno, L., \& Nosal, T. (2011). Weather or not to cycle: Temporal trends and impact of weather on cycling in an urban environment. Transportation Research Record: Journal of the Transportation Research Board, (2247), 42-52.

Morency, C., Trépanier, M., Godefroy, F. (2011) Insight into the Montreal bikesharing system. Transportation Research Board 90th Annual Meeting.

Neutens, T., Delafontaine, M., Scott, D.M., De Maeyer, P. (2012) An analysis of day-to-day variations in individual space-time accessibility. Journal of Transport Geography, 23, 81-91.

Nikitas, A., Wallgren, P., Rexfelt, O. (2016). The paradox of public acceptance of bike sharing in Gothenburg. Proceedings of the Institution of Civil Engineers-Engineering Sustainability, 169(3), 101-113.

Ogilvie, F; Goodman, A. (2012) Inequalities in usage of a public bicycle sharing scheme: Socio-demographic predictors of uptake and usage of the London (UK) cycle hire scheme. Preventive medicine, 55 (1) 40-5.

Parkes, S.D., Marsden, G., Shaheen, S.A., Cohen, A.P. (2013) Understanding the diffusion of public bikesharing systems: evidence from Europe and North America. Journal of Transport Geography, 31, 94-103.

Pas, E.I. (1988) Weekly travel-activity behavior. Transportation, 15, 89-109.

Pas, E.I. and Koppelman, F.S. (1986) An examination of the determinants of day-to-day variability in individuals' urban travel behavior. Transportation, 13, 183-200.

Pas, E.I. and Sundar, S. (1995) Intrapersonal variability in daily urban travel behavior: Some additional evidence. Transportation, 22, 135-150.

R Core Team (2016) R: A language and environment for statistical computing. R Foundation for Statistical Computing, Vienna, Austria. URL https://www.R-project.org/.

Ricci, M. (2015). Bike sharing: A review of evidence on impacts and processes of implementation and operation. Research in Transportation Business \& Management, 15, 28-38.

Schlich, R. and Axhausen, K.W. (2003) Habitual travel behavior: evidence from a six-week travel diary, Transportation, 30 (1), 13-36.

Schönfelder, S. and Axhausen, K.W. (2010) Urban rhythms and travel behavior: Spatial and temporal phenomena of daily travel. Ashgate Publishing Ltd.

Shaheen, S., Guzman, S., Zhang, A. (2010) Bikesharing in Europe, the America, and Asia: past, present, and future. Transportation Research Record 2143, 159-167.

Shaheen, S., Martin, E., Cohen, A. (2013) Public bikesharing and modal shift behavior: a comparative study of early bikesharing systems in North America. International Journal of Transportation. 1, 35-54.

Train, K.E. (2009) Discrete choice methods with simulations, $2^{\text {nd }}$ edition, Cambridge University Press.

Vogel, M., Hamon, B., Lozenguez, G., Merchez, L. Abry, P., Barnier, J., Borgnat, P., Flandrin, P., Mallon, I., Robardet, C. (2014) From bicycle sharing system movements to users: a typology of Vélo'v cyclists in Lyon based on large-scale behavioral dataset. Journal of Transport Geography, 41, 280-291. 